\title{
Budaya dan Pembangunan Ekonomi di Jepang, Korea Selatan dan China
}

\author{
Citra Hennida, Reza Akbar Felayati, Sri Harini Wijayanti, \\ Alfionita Rizky Perdana
}

Departemen Hubungan Internasional, Universitas Airlangga

\begin{abstract}
ABSTRAK
Berbeda dengan pembangunan di Barat yang lebih menekankan fitur-fitur penghargaan terhadap individu sebagai pendorong inovasi, keberhasilan pembangunan di Jepang, Korea Selatan dan China lebih merupakan dorongan kombinasi antara fitur penghargaan individu dengan budaya lokal Konfusian. Sistem nilai yang ada dalam lembaga-lembaga di tiga negara Asia tersebut menyediakan nilai-nilai Konfusian. Artikel ini berargumen bahwa proses kombinasi kebudayaan ini terjadi melalui dorongan sejarah peristiwa humiliationdimana budaya lokal dan budaya pendatang mengalami proses seleksi sebelum diserap. Dengan melakukan identifikasi proses humiliation pada sejarah Jepang, Korea Selatan, dan China ditemukan fitur-fitur budaya baruseperti fukoku kyohei, wakon yosai, datsua nyuo, bunmei yang hadir di Jepang; han, family law dan hallyu di Korea Selatan, dan pragmatisme, sosialisme ala China dan neo-konfusianisme di China.
\end{abstract}

Kata-kata kunci: budaya dan pembangunan ekonomi, proses penghinaan, konfusian

Different from development in the West that tends to promote innovation by giving more appreciation towards individual achievement, the development success in Japan, South Korea, and China have been more of a combination between individual achievements with local Confucian culture.The value systems that exist within the institutions prodided by Confucian values in these three East Asian countries. This article argues that this combining cultural process has gone through historical humiliation stages where local and importing culture were selected before they were being absorbed. These three East Asian countries combine the "Western" perspectives on social, economic and political institution and the Confucian value system. It finds some "new" cultural features such as fukoku kyohei, wakon yosai, datsua nyuo, bunmei keika in Japan; han, family law and hallyu in South Korea; pragmatism, Chinese socialism, and neo-confucianism in China.

Keywords: culture and economic development, humiliation process, confucianism 


\section{Pendahuluan}

Setelah Perang Korea, Korea Selatan adalah negara miskin, bahkan lebih miskin dibandingkan dengan Korea Utara. Pada tahun 1960-an, hasil produksi Korea Selatan masih sangat terbatas dan lebih banyak tergantung pada ekspor produk primer serta bantuan luar negeri. Di tahun 1990-an pertumbuhan ekonomi Korea Selatan tumbuh pesat, produk domestik brutonya (PDB) adalah limabelas kali PDB di tahun 1960-an. Sementara itu, China diawal pemerintahan Deng Xioping,yang melakukan perjalanan ke selatan pada akhir tahun 1970-an adalah China yang miskin dan terbelakang. Dua puluh tahun kemudian China berubah menjadi negara modern dengan pertumbuhan sampai dua digit dan sekarang adalah negara dengan ekonomi terbesar kedua di dunia. Di lain fihak, Jepang pada akhir Perang Dunia II adalah negara yang hancur karena serangan bom nuklir. Kehancuran Hiroshima dan Nagasakikarena bom nuklir mengubah Jepang dari salah satu negara imperialis dunia menjadi negara yang hancur dan pasifis. Tiga puluh tahun kemudian Jepang hadir dan memimpin barisan negara industri baru (new industrial countries, NICs). Negara-negara Asia Timur ini tidak saja dapat tumbuh maju tapi juga mampu mempertahankan pertumbuhannya. Negara-negara ini berhasil mengatasi krisis finansial di tahun 1997-1998 dan resesi global di tahun 2008. Tahun 2010 Korea Selatan dan China mencatat pertumbuhan sebesar 6,3\% dan 10,3\% (Magnus 2013).

Pertanyaannya, mengapa negara-negara ini bisa lebih maju dibandingkan dengan negara-negara lainnya, bahkan jika semua faktor ekonomi diikutkan?Pertanyaan ini tidak cukup dijawab dengan teoriteori pembangunan ekonomi. Ada aspek lain yang perlu dipertimbangkan yaitu budaya. Aspek hubungan antara budaya dan pertumbuhan ekonomi dengan fokus pada tiga negara di Asia Timur inilah yang menjadi fokus tulisan ini. Asia Timur dipilih karena budaya kolektifnya yang kuat, yang berbeda dengan konsepsi pemikir-pemikir budaya dalam pembangunan yang lebih menekankan pada budaya individualistis (kebebasan individu) yang dianggap lebih inovatif dalam mendorong pertumbuhan.

\section{Hubungan antara budaya dan pembangunan ekonomi}

Hubungan antara budaya dan pembangunan ekonomi sudah lama menjadi perhatian para ahli. Para pemikir ekonomi klasik menggunakan penjelasan budaya untuk mengamati fenomena ekonomi. Budaya didefinisikan sebagai kebiasaan, kepercayaan dan nilai-nilai yang dianut oleh kelompok etnis, kelompok agama dan kelompok sosial yang cenderung tidak berubah dari generasi ke generasi (Guiso, Sapienza, 
Zingales 2006). Max Weber mengungkapkan bahwa agama krusial bagi tumbuhnya kapitalisme. Max Weber dalam bukunya "The Protestant Ethic and the Spirit of Capitalism" berpendapat bahwa etika kristianiti (Protestan)yang melekat pada masyarakat Eropa mendorong kemajuan dan modernitas Eropa. Weber melihat bahwa budaya adalah faktor pendorong dibalik beragamnya pertumbuhan ekonomi. Pemikiranpemikiran ekonomi pada akhir tahun 1990-an dan awal tahun 2000-an menemukan bahwa pembangunan tidak hanya didorong oleh hadirnya institusi-institusi formal namun juga oleh hadirnya institusi-institusi informal dimana budaya hadir dan berperan di dalamnya.

Hubungan antara budaya dan pembangunan bisa diartikan menjadi dua, baik sebagai agen perubahan utama maupun sebagai target perubahan. Budaya dijadikan sebagai agen perubahan utama disebabkan oleh beberapa faktor, di antaranya (1) budayamemproduksi kondisi material karena budaya memproduksi simbol dan aksi; dan (2) budaya mampu mendorong individu untuk merekonstruksi struktur institusi dan lingkungan materialnya, dalam hal ini individu menunjukkan respon kreatifnya (Goldstone 1991; Greif 1994; Barro dan McCleary 2003). Hubungan antara budaya dan pembangunan juga memperlihatkan bahwa budaya adalah target perubahan itu sendiri (Morishima 1982, Xing 2001). Augusto Salazar Bondy (dalam Harrison 1985) menyatakan bahwa underdevelopment adalah masalah cara pikir dan bentuk-bentuk dari ketidakmampuan adaptasi, oleh karenanyahal itu harus diubah.

Di Asia Timur, budaya kolektif muncul sebagai budaya yang dipilih untuk dipromosikan sekaligus menjadi target untuk diubah.Konfusian dipandang sebagai budaya yang berpengaruh pada pembangunan ekonomi di masyarakat Asia Timur (Pye 1990; Allen et al 2007; Adam dan Vernon 2007; Power et al 2009). Berger (1986) mempresentasikan ada dua faktor yang mempengaruhi kesuksesan Asia Timur yaitu pengalaman Asia Timur yang tidak hanya didukung oleh budaya Konfusian melainkan juga ada pengaruh budaya Barat; dan kombinasi keduanya memunculkan etika kerja yang mendorong kepada pembangunan. Hal serupa dikemukakan oleh Hahm dan Paik (2003), yang melihat bahwa pembangunan di negara-negara Asia Timur adalah dengan mengkombinasikan nilai-nilai Barat dengan nilai-nilai Timur. Kelembagaan sosial, ekonomi dan politik merupakan impor dari Barat sedangkan sistem nilai yang ada dalam institusi tersebut disediakan oleh nilai-nilai Konfusian. Inilah yang membedakan kapitalisme Asia Timur.

\section{Pembentukan Budaya melalui Humiliation}

Kombinasi Barat-Timur terjadi melalui proses humiliation yang dimaknai secara nasional dan diterjemahkan sebagai proses untuk 
mendisiplinkan perilaku pihak-pihak yang merasa dipermalukan dengan cara menyerang dan merendahkan persepsi akan dirinya (self) dan meninggikan persepsi akan orang lain (others) sebagai lebih baik (Saurette 2006). Pada akhirnya self tidak hanya mengkonstruksi others sebagai musuh, melainkan juga bagaimana others mengkonstruksi self dalam berbagai cara yang kompleks seperti yang terjadi di China. Sebagai contohnya, pengaruh asing (others) sangat kuat peranannya dalam mengkonstruksi China dari persepsi sebagai pusat dunia menjadi the sick man of Asia setelah perang Opium; Korea Selatan yang selama ini mandiriterpaksa berhutang kepada IMF untuk mengatasi persoalan ekonominya (Callahan 2004). Peristiwa-peristiwa tersebut adalah proses humiliation yang tidak berbentuk materi tapi lebih kepada proses yang sifatnya simbolik. Saurette (2006) mengemukakan bahwa proses humiliation dapat berfungsi sebagai pembeda antara situasi lama dan baru. Secara lebih spesifik Saurette menyebutnya sebagai komitmen emosional yang melibatkan penghargaan dan perasaan dipermalukan. Keinginan-keinginan untuk mendapatkan kehormatan kembali mendorong negara untuk maju, dalam artian kembali menggali nilainilai yang ada dalam masyarakatnya dan menyerap nilai-nilai dari luar yang dianggap sesuai dengan situasi internasionalnya. Pendapat serupa dikemukakan oleh Crawford (2000) yang menganggap bahwa peran emosional mendorong negara untuk berprilaku seperti misalnya keterlibatan dalam perang, bekerjasama, menumbuhkan nasionalisme dan patriotisme sampai kepada penggunaan sebagai modal pendorong pembangunan. Peran perasaan-perasaan emosional dalam pembangunan ini dianggap sebagai hal yang tidak rasional yang perlu disembuhkan dengan mengubah psikologi sosial kearah praktik sosial yang perlu dipahami dalam narasi historisnya (Callahan 2004).

Penelusuran melalui narasi historis dimulai pada masa pembentukan ideologi (Bhabha 1990). Dalam masa pembentukan ideologi ini ada budaya yang dihilangkan dan ada budaya yang diunggulkan. Ada penggabungan antara proses seleksi internal dengan impor dari asing. Inkster (2001) menyebutnya sebagai cultural engineering yang kurang lebih mencakup seperangkat prosedur budaya terpilih yang kemudian digunakan oleh elit dalam bentuk aksi, kebijakan dan pernyataan agenda yang terlihat dalam perilaku sehari-hari. Cultural engineering berfokus pada seleksi, spesifikasi dan publikasi dari ideologi tertentu. Prosesproses ini dijelaskan Gluck (1985) sebagai formasi ideologi yang melibatkanusaha sadar yang dilakukan oleh masyarakat dalam negara.Budaya asing diperlukan di masa lalu karena ada budaya masa laluyang kurang sesuai ketika dihadapkan pada tantangan masa depan. Proses ini biasanya terjadi pada situasi darurat dan ketika ada intrusi asing. Disinilah proses humiliation terjadi (Inkster 2001). 
Periode humiliation di masing-masing negara tidaklah sama, tergantung apakah intrusi asing tersebut sensitif terhadap budaya lokal atau tidak; dekat atau tidak dengan persepsi akan penghormatan dan penghargaan (Saurette 2006). Jepang dimulai dari kedatangan Komodor Perry; China dalam beberapa periode intervensi asing yang lantas memecah wilayahwilayah China dan menjauhkan dari konsepsi negara peradaban; Korea dalam periode kolonisasi Jepang dan krisis ekonomi yang mengharuskan Korea Selatan berhutang kepada Dana Moneter Internasional.

\section{Jepang}

Di Jepang, periode humiliation dimulai di era Restorasi Meiji pada tahun 1868. Kebudayaan Jepang di era tersebut mengalami tantangan besar dari kemunculan budaya Barat yang merupakan konsekuensi dari dibukanya Jepang. Diawali dari kedatangan pasukan Amerika Serikat yang dipimpin oleh Komodor Matthew C. Perry, Jepang dipaksa untuk mengakui keunggulan Amerika Serikat dalam hal teknologi dan kemajuan. Seiring dengan kedatangan pasukan Komodor Perry, pertanyaan besar mengenai identitas, kapabilitas maupun arah pembangunan Jepang pun semakin membesar (Cullen 2003). Identitas Jepang sebagai negara ke-shogun-an yang kuat di dunia, sebagaimana mereka percayai, menjadi runtuh. Saat itu Jepang melakukan restorasi dan menggali lagi nilai-nilai Jepang untuk kemudian diselaraskan dengan ide-ide Barat yang lebih progresif. Salah satu reaksi dari periode humiliation tersebut adalah lahirnya empat motto yang mendeskripsikan masyarakat Jepang dalam berpikir dan bertindak di era sebelum dan sesudah Restorasi Meiji, yaitu fukoku kyohei atau memperkaya negara dan memperkuat milter, wakon yosai atau jiwa Jepang dengan kemampuan Barat, datsua nyuo atau tinggalkan Asia dan bergabung dengan Eropa, serta bunmei keika atau menjadi beradab (Cullen 2003).

Fukoku kyohei adalah ide yang menekankan pada penguatan aspek militer di dalam negara agar negara dapat maju. Kedatangan Komodor Perry dengan kapal perang dan persenjataan modern membuat Jepang gamang. Hal ini kemudian mendorong Jepang untuk mulai memperkenalkan teknologi dan sains dari Barat dalam upaya untuk mengatasi ancaman dari Barat. Jepang berupaya untuk memanfaatkan pencapaian Barat dan tetap mempertahankan sisi Jepang mereka untuk tujuan yang lebih besar, yaitu persaingan dengan Barat. Motto kedua adalah wakon yosei yang merupakan ide mengenai kepemilikan jiwa dan semangat Jepang untuk memiliki kemampuan layaknya masyarakat Barat. Dalam hal ini, Jepang berupaya untuk mengkolaborasikan mentalitas tradisional Jepang dengan kemajuan teknologi Barat sebagai solusi dari kegamangan Jepang di era Restorasi Meiji. Mengutip dari 
Sakuma Zozan pada tahun 1854 (dalam Kitahara 1986), bahwa mempelajari moralitas Timur dan teknologi Barat dan memberikan bangsa hasil positif dari kolaborasi tersebut adalah hal yang diperlukan oleh Jepang. Dengan kata lain, Jepang hanya menggunakan teknologi Barat sebagai alat semata, namun Jepang tetap bertahan dengan akar identitas dan budaya mereka. Hal ini dianggap sebagai upaya identifikasi diri Jepang untuk bertahan. Sebagaimana diketahui bahwa ancaman terbesar Jepang berasal dari Amerika Serikat dan Rusia. Jepang melihat bahwa dengan mengidentifikasi diri sebagai bagian dari kedua negara tersebut, memungkinkan Jepang untuk bertahan. Identifikasi diri (self) ini kemudian tidak hanya terjadi di tingkat negara, namun juga di tingkat masyarakat dan individu Jepang. Kelompokkelompok ekstremis yang pada awalnya menolak segala bentuk teknologi Barat, pada akhirnya menjadi mendukung terbukanya Jepang. Hal ini berdampak pada kemunculan motto ketiga, yaitu datsua nyuo atau tinggalkan Asia dan bergabung dengan Eropa yang menggambarkan proses identifikasi Jepang terhadap Barat ke tingkat yang lebih jauh dari sekedar pengadopsian teknologi semata. Motto ketiga tersebut tidak lepas dari proses yang dilandasi motto keempat yaitu bunmei keika atau menjadi beradab. Salah satu aspek bunmei kaika mengajarkan untuk mengubah pola pikir dan ide-ide lama, terlepas dari perbedaan rasial. Hal ini mendasari perubahan yang semakin cepat di Jepang dalam mengidentifikasi diri mereka dengan Barat. Kemunculan nilai-nilai Barat seperti kekristenan, kebebasan dan hak sipil, hingga demokrasi pun tidak terhindarkan (Kitahara 1986).

Tidak berhenti pada empat motto seperti yang dijelaskan sebelumnya, wujud lain dari reaksi atas proses penghinaan Jepang direalisasikan dalam bentuk imitasi model keorganisasian Barat atau Western Organizational Model dalam pembangunan di Jepang. Ketika Jepang memulai pembangunan pada awal 1870 -an untuk memulai persaingan dengan Barat, terjadi transformasi sosial, yang disebut Kenneth Boulding (dalam Westney 1987) sebagai proses organizational revolution atau revolusi organisasi. Didefinisikan sebagai peningkatan yang signifikan dalam jumlah, ukuran, dan kekuatan organisasi dari berbagai sektor. Revolusi organisasi dianggap merupakan fondasi utama dari perubahan politik, ekonomi, dan budaya yang besar di suatu negara dari abad ke-19 hingga abad ke-20. Di Jepang, revolusi organisasi merupakan dasar ekspansi mereka dalam berbagai kegiatan dan kapasitas negara, dan merupakan katalisator dari munculnya konsep perusahaan bisnis modern yang mengandung banyak unit operasi yang berbeda dan dikelola oleh hierarki eksekutif; dengan tujuan untuk menciptakan pola-pola baru konsumsi, rekreasi, serta kegiatan politik (Westney 1987). Imitasi yang dilakukan Jepang ini pun tidak lepas dari wacana dan diskursus pembangunan di berbagai negara Barat pada saat itu, yang memang menekankan pada pembangunan keorganisasian 
dalam skala besar seperti yang terjadi di Perancis, Inggris dan Amerika Serikat (Westney 1987).

\section{Korea Selatan}

Korea setidaknya memiliki empat periode humiliation yang berpengaruh secara signifikan dalam perkembangan ekonomi dan negaranya.Pertama adalah era kolonialisme Jepang (1910-1945).Kemenangan Jepang atas Rusia berdampak pada Korea yang kemudian menjadi wilayah protektorat sebelum akhirnya benar-benar menjadi wilayah koloni Jepang. Kolonialisme yang terjadi di Korea secara tidak langsung menciptakan rasa nasionalisme yang mendalam untuk bisa bebas dan merdeka menjadi negara berdaulat penuh yang didorong oleh ajaranajaran lokal atau Tohak (Shamanisme dan Konfusianisme) serta ajaran Kristen yang mengalami indigenisasi atau Sohak. Nasionalisme muncul didorong oleh adanya kebijakan pemerintah kolonial Jepang yang menggunakan slogan nissen yuwa yang berarti harmoni antara Jepang dan Korea, dimana penduduk Korea mengalami pemaksaan asimilasi budaya Jepang (Seth 2011). Penerapan kebijakan ini dimulai pada tahun 1919 dimana setiap penduduk Korea diperintahkan untuk mendaftarkan diri di badan resmi pemerintah Jepang untuk mendapatkan nama Jepang. Sebagian besar masyarakat dilarang menggunakan bahasa Korea dan didorong untuk menggunakan bahasa Jepang. Selain itu, pemerintah kolonial juga menerapkan kebijakan kultural atau bunka seiji pada tahun 1920 yang mereformasi pola pendidikan di Korea. Beberapa kebijakan buruk pemerintah kolonial mendorong munculnya cultural nationalist pada tahun 1922 dimana arah perjuangan pembebasan kolonialisme tidak dilakukan secara politis melainkan secara kultural dengan melibatkan artis, seniman, dan pelaku seni lainnya (Seth 2011). Hal ini juga mendorong masyarakat untuk memanfaatkan teknologi Jepang yang ada untuk digunakan, diperbaiki, dan diterapkan kembali paska berakhirnya penjajahan seperti sistem ekspor, infrastruktur yang semakin dibenahi, penghapusan perbudakan, dan penciptaan atmosfer kosmopolit. Berakhirnya kolonialisme Jepang di Korea pada tahun 1945 secara tidak langsung telah menciptakan sistem ekonomi yang terstruktur, industri yang tergolong maju di bagian utara, serta sistem pertanian yang lebih maju. Masa kolonialisme ini juga telah menimbulkan han pada masyarakat Korea, yaitu rasa benci pada mereka yang telah menyakiti secara turun-temurun, yang kemudian menjadi dasar dalam mengejar ketertinggalan dan membangun ekonomi negara di masa depan (Hong 2014).

Periode humiliation kedua adalah pada masa Perang Dingin dimana terjadi partisi antara Korea Utara dan Korea Selatan di Semenanjung Korea.Setelah partisi, kondisi dalam negeri Korea Selatan sangat miskin, industri dan lahan pertanian yang dibangun pada masa kolonisasi 
Jepang banyak berada di wilayah utara (Seth 2011). Berakhirnya Perang Korea meningkatkan jumlah populasi masyarakat urban dan meningkatkan korupsi di tingkat pemerintahan. Dalam usahanya, Presiden Rhee menciptakan Dewan Pertumbuhan Ekonomi untuk mengatasi inflasi dan meningkatkan pertumbuhan dengan dana bantuan Amerika Serikat (Seth 2011). Hong (2014) menjelaskan bahwa ajaran Konfusianisme dirasa berbelok karena pemerintah menggunakannya sebagai alat politik, salah satu dampaknya adalah korupsi akut di pemerintahan.Student Revolution yang menumbangkan pemerintahan Rhee yang korup dan memalukan karena banyaknya aliran dana asing yang masuk pada tahun 1960. Dilantiknya Park Chung Hee sebagai Presiden Korea Selatan yang baru menandai dimulainya era ekonomi baru. Presiden Park menggunakan motto First Five-Year Plan atau charip kyongjeyang berusaha menciptakan sistem ekonomi yang lebih independen, berdaulat, dan demokratis (Seth 2011).

Presiden Park sendiri membuat kebijakan ini dengan mengacu pada kemajuan ekonomi Jepang yang di satu sisi dapat membangun perekonomian dalam negeri dengan tidak terlalu bergantung pada bantuan asing.Hal ini menjelaskan keberhasilan Presiden Park dalam mendorong terbentuknya kerjasama triple helix antara pemerintah, korporasi, dan masyarakat dalam meningkatkan ekonomi dalam negeri. Menggunakan prinsip-prinsip utama Konfusianisme pada kerja keras, loyalitas dan hierarki, Presiden Park mampu mendorong setiap individu untuk menyadari posisinya masing-masing di dalam masyarakat sekaligus menjadi motor untuk mencapai pertumbuhan ekonomi. Selain itu, didorong oleh rasa han untuk menyaingi kemajuan Jepang dan berlandaskan pada asas-asas Konfusianisme, pemerintah memberikan dana bantuan yang cukup besar pada korporasi yang dirasa mampu menunjang pertumbuhan ekonomi. Hal ini kemudian menciptakan chaebol sejak tahun 1970-an. Dalam strata Konfusianisme, korporasi dianalogikan sebagai anak yang harus berbakti dan berusaha keras demi negara sebagai ayah. Chaebol dengan mudah mendapatkan kredit, penggunaan fasilitas negara untuk urusan bisnis, serta keringanan dalam pajak impor bahan-bahan produksi (Seth 2011). Norma-norma penghormatankepada yang lebih tua, menjadi warga negara yang baik dan bekerja keras, serta mencintai alam telah ditanamkan sejak kecil melalui pendidikan moral yang disebut doduk (Hong 2014).

Pertumbuhan korporasi dan chaebol yang signifikan ini seakan berhenti ketika Korea Selatan memasuki periode yang ketiga saat terjadinya krisis pada tahun 1980. Pembunuhan Presiden Park ditahun 1979, adanya lonjakan harga minyak yang menyebabkan terjadinya inflasi dalam negeri di tahun yang sama, serta hutang luar negeri pada Jepang yang digunakan untuk pembangunan selama pemerintahan Presiden Park membuat negara ini berada dalam ketidakpastian (Seth 2011). Warga 
Korea Selatan yang terpuruk ini merasa terhina akibat banyaknya hutang terhadap bekas negara penjajahnya dulu sehingga dengan didorong oleh etos Konfusianisme yang menekankan pada kerja keras, disiplin, dan kolektivitas, warga Korea Selatan kembali membangun ekonomi dalam negerinya. Pemerintahan dan birokrasi yang terpusat serta kebijakan nasional yang kuat membuat Korea Selatan perlahan bangkit. Selain itu, dengan mengutamakan pendidikan pemerintah berusaha membentuk masyarakat yang lebih terdidik, sehingga setiap individu dipastikan bekerja keras sesuai dengan posisinya masingmasing dalam masyarakat. Selain itu, Family Law juga mulai diresmikan ditahun 1989 yang kemudian memberikan hak yang sama bagi laki-laki dan perempuan dalam berbagai bidang seperti rumah tangga, pekerjaan, dan pendidikan.

Periode keempat muncul pada saat krisis finansial tahun 1997. Korea Selatan merasa terhina karena mereka terpaksa harus meminjam dana hingga mencapai USD 57 miliar pada Desember 1997 dari Dana Moneter Internasional yang kemudian dikenal sebagai Hari Memalukan Nasional (Hong 2014). Dalam budaya Konfusian, berhutang adalah hal yang memalukan. Sistem ekonomi dalam negeri yang berpusat pada pemerintah dan chaebol atau yang disebut Korea Inc. ini kemudian dituntut untuk mengalami reformasi besar sejak terjadinya krisis.Korea Inc. melakukan reformasi dengan merubah strategi diversifikasi menjadi strategi yang lebih spesifik. Pemerintah juga mulai menciptakan kebijakan kultural sejak berakhirnya krisis yang bertujuan untuk meningkatkan pendapatan dalam negeri yang dapat digunakan untuk melunasi hutang serta menciptakan citra baik yang dapat mempengaruhi para investor asing bahwa Korea Selatan tidak lagi terjebak dalam krisis (Hong 2014). Fenomena Hallyu atau Korean Wave kemudian muncul.

\section{China}

China setidaknya melewati lima periode humiliation. Periode pertama terjadi pada masa Perang Opium. Pada fase yang terjadi sejak tahun 1839 hingga 1860 ini China mendapat serangan dari negara-negara Barat, dimulai dari Inggris pada Perang Opium I dan kemudian disusul oleh Prancis di Perang Opium II. Keberadaan negara-negara asing seperti Inggris dan Prancis memaksa China untuk menyepakati beberapa hal, di antaranya adalah partisi wilayah. Adanya partisi ini kemudian berimplikasi pada munculnya kesadaran dalam internal China bahwa mereka tidak bisa lagi menjadi isolasionis. Apabila mereka ingin maju, maka cara yang harus dilakukan adalah dengan mempelajari nilainilai Barat (Goldfinger 2006). Ini berdampak pada pembentukan kebijakan pemerintah China. Para cendekiawan mulai mempelajari nilai-nilai Barat dan rekomendasi dari para cendekiawan ini tertuang 
dalam regulasi pendirian industri-industri baru di China. Pendirian industri baru ini juga harus beragam agar terjadi persaingan dalam pasar. Awal-awal penerapan masih dikombinasikan dengan industri atau pabrik dikelola oleh para kaum feodal. Nilai-nilai Konfusianisme yang berupa kekeluargaan masih dapat ditemukan dalam periode ini. Meski demikian, di satu sisi muncul kesadaran baru di antara para intelektual saat itu bahwa dengan mengadopsi nilai-nilai Barat, akan lebih mudah bagi China melakukan modernisasi. Oleh sebab itu, didukung dengan fakta bahwa praktik-praktik bisnis berdasar keluarga adalah legasi korup, pemerintah kemudian memutuskan untuk lebih mengadopsi nilai-nilai Barat (Gronewold 2009). Kapitalisme Barat dengan membebaskan perusahaan bekerja kemudian menjadi salah satu contoh kebijakan yang dilakukan oleh pemerintah. Dengan kata lain kemudian nilai-nilai Konfusianisme menjadi tereduksi secara perlahan.

Periode kedua terjadi di masa invasi Jepang ke China tahun 1895 hingga 1937. Invasi Jepang ke China telah membawa dampak masuknya budaya dan nilai dari Jepang.Budaya militerisme dan bushido yang dibawa Jepang masuk dan diserap oleh China. Salah satu kebijakan yang kemudian berkaitan dengan budaya dan nilai di China adalah adanya kebijakan Hundred Days Reform. Peristiwa ini terjadi sebagai bentuk reformasi internal China.Muncul kesadaran bahwa reformasi yang terjadi di China seperti di era Perang Opium, hanya mengakomodasi nilai-nilai Barat untuk diadopsi (Rosker 2014). Selain itu, dari dalam China terbentuk rasa nasionalisme yang tinggi. Rasa nasionalisme dan patriotism ini disebutkan bahkan menggeser familialisme, regionalisme, dan lokalisme (Lary 2010). Mirip dengan Korea, rasa nasionalisme dan patriotism yang tinggi ini menjadi salah satu alasan mengapa masyarakat China memiliki rasa anti terhadap Jepang. Rasa nasionalisme dan patriotisme yang tinggi ini yang membangkitkan semangat pergerakan serta kesadaran masyarakat China dalam bernegara. Nilai dan budaya Konfusianisme sendiri tidak terlalu muncul karena yang menjadi fokus bukan pada reformasi mengembalikan nilainilai Konfusianisme, melainkan bagaimana mereformasi China agar tidak hanya nilai dan budaya Barat saja yang diadopsi.

Periode ketiga adalah era perang sipil (1927-1950). Pada periode ini, budaya yang muncul adalah nasionalisme dan patriotisme yang masih begitu kuat sebagai bagian dari dampak invasi Jepang ke China (Lary 2010). Budaya dan nilai ini kemudian terefleksi pada kebijakan One China Policy yang digagas sebagai bagian untuk mencegah lepasnya Taiwan dari China. Seperti diketahui, sejak pecah perang sipil di China yang melibatkan Partai Kuomintang sebagai partai nasionalis dan Partai Komunis China, terjadi peristiwa larinya para pemimpin dan simpatisan Partai Kuomintang ke Taiwan. Sejak saat itu, Taiwan yang didiami oleh elit dan simpatisan Kuomintang ini menyatakan diri Taiwan sebagai 
negara yang independen dan bukan bagian dari China. Menanggapi respon ini, Deng Xiaoping sebagai salah satu elit Partai Komunis China kemudian menggagas One China Policy sebagai bagian dari reunifikasi dengan Taiwan secara damai. Implikasinya kemudian dibukanya dan difasilitasinya investasi dari China ke Taiwan.

Periode keempat adalah era Chinese Great Famine mulai tahun 19591961. Perlu diketahui bahwa dimulainya kekuasaan Partai Komunis di China tahun 1949 telah menyebabkan Neo-Konfusianisme dihapus secara total oleh pemerintah China (Adler 2011). Hal ini disebabkan karena Neo-Konfusianisme dipandang sebagai legasi feodal yang merupakan musuh dalam siklus Marxisme. Di fase awal ini, pemerintah China secara total mengadopsi model pembangunan ala Soviet yang berorientasi pada industri sosialisme sebagai garda terdepannya (Rosker 2014). Namun kemudian, sejak tahun 1956 pemerintah China mulai menggunakan model pembangunannya sendiri yang berorientasi pada agrikultur, bukan lagi pada industri sosialisme (Rosker 2014). Namun demikian nafas sosialisme masih dipertahankan dalam sektor agrikultur, salah satunya yang nampak adalah dari bagaimana hasil pertanian dikumpulkan secara kolektif per daerah untuk kemudian didistribusikan secara adil menurut konsepsi pemerintah China.

Dalam proses pembangunan yang menggunakan preskripsi China sendiri, terjadi peristiwa kelangkaan pangan yang kemudian dikenal sebagai Great Chinese Famine, Kebijakan pemerintah China di bawah pimpinan Mao Zedong yang menggunakan preskripsi Marxisme utopian ini yang kemudian menyebabkan peristiwa tersebut tidak dapat dihindari. Budaya dan nilai Marxisme kemudian diadopsi dan disesuaikan dengan pemikiran Mao Zedong ini menghasilkan sebuah ideologi yang kemudian dikenal sebagai Maoisme. Maoisme yang begitu kuat mengakar dalam kehidupan masyarakat China. Sementara itu, dari dalam muncul budaya loyalty compensation yang dalam prakteknya banyak digunakan pemerintah China untuk menutupi alasan-alasan terjadinya Great Famine kepada masyarakatnya. Loyalty compensation merupakan budaya yang menggambarkan bagaimana anggota Partai Komunis di China dapat menduduki jabatan elit di masing-masing daerah dengan membayar dan memberi kompensasi pada partai (Lin dan Yang 1998). Budaya semacam ini dipertahankan dengan tujuan untuk menjaga kestabilan di China sendiri. Mengingat Maoisme menekankan pada kepatuhan yang besar dan kepercayaan masyarakat yang harus diberikan pada pemerintah, maka dengan budaya dan nilai semacam ini pembangunan di China dinilai oleh pemerintahnya dapat terus dilanjutkan.

Periode terakhir adalah era Revolusi Budaya (1966-1975). Mao menggagas program lain untuk mengembalikan kepercayaan 
masyarakat China. Program baru yang digagas oleh Mao ini dikenal sebagai Revolusi Budaya.Dalam Revolusi Budaya paham Komunisme dan Sosialisme masih menjadi nilai dan budaya yang diadopsi oleh China.Ini dapat diamati dari salah satu budaya kolektif misalnya dalam hal pertanian, hasil pertanian dikumpulkan secara kolektif dan diserahkan pada pemerintah sebelum kemudian dijual dan hasilnya didistribusikan kembali oleh pemerintah pusat. Hanya saja, perbedaannya adalah jika di Uni Soviet, basisnya adalah buruh, sementara di China basisnya adalah kaum tani. Maoisme masih begitu kuat dalam fase ini, budaya dan nilai yang begitu terlihat kemudian di antaranya family-background oriented dan unquestioning faith and obedience (Lipman dan Harrell 1990). Dua nilai dan budaya yang mengakar dari internal China ini yang menjadikan proses pembangunan dalam kerangka berpikir pemerintah China saat itu dapat berjalan.

Periode-periode humiliation ini memunculkan selektivitas terhadap budaya-budaya yang lantas digunakan untuk mendorong pembangunan selanjutnya. Budaya dan nilai yang dipertahankan dari periode-periode tersebut adalah pragmatisme, Sosialisme ala China, dan NeoKonfusianisme. Sementara itu, nilai dan budaya yang ditinggalkan di antaranya adalah isolasionisme, Maoisme, ofisialisme, dan entrepreneurial familism. Pragmatisme diadopsi oleh China sejak era Deng Xiaoping. Pragmatism China muncul dan terefleksi dari kebijakan pemerintahnya seperti melakukan keterbukaan (Open Door Policy) dengan mengizinkan masuknya investasi asing ke China. Ini sekaligus menghapus budaya isolasionisme China di era Mao Zedong dan berkaitan dengan Sosialisme ala China yang menggambarkan bagaimana China secara sistem ekonomi telah mengarah pada model Kapitalisme. Namun Kapitalisme yang dijalankan oleh China tersebut berbeda dari Kapitalisme Barat, demikian halnya dengan sistem pemerintahan Sosialisme dan Komunisme yang dijalankan oleh China berbeda dari apa yang ada di Uni Soviet.

Kolektivitas masih muncul sebagai bagian dari budaya yang bertahan dalam masyarakat China dan berkontribusi dalam pembangunan di negara ini. Sementara itu, budaya officialism yang merupakan budaya penempatan kelompok atau orang-orang tertentu dalam sebuah kedudukan birokrat mulai ditinggalkan. Ini terlihat dari kebijakan pemerintah China melakukan empat transformasi yang bertujuan untuk menghilangkan budaya korupsi yang menjadi penghambat pembangunan di China. Maoisme juga mulai ditinggalkan. Demikian halnya dengan budaya bisnis yang didasarkan pada latar belakang keluarga juga mulai ditinggalkan. Ini terefleksi dari upaya pemerintah China untuk kemudian mengalihkan model bisnis menjadi lebih terbuka bagi pihak luar dan bukan hanya sekedar collective enterprise maupun 
state enterprise. Salah satu cara yang dilakukan adalah melalui jointventure.

Konfusianisme yang kemudian bertransformasi menjadi NeoKonfusianisme menjadi nilai dan budaya yang kembali diadopsi oleh pemerintah China.Setidaknya, kebangkitan Neo-Konfusianisme telah dimulai sejak tahun 1980-an. Pada saat itu, seiring dengan keterbukaan dan kebebasan yang diberikan pemerintah di bawah pimpinan Deng Xiaoping kepada masyarakat China membuat beragam filosofi diizinkan untuk dipelajari. Tidak terkecuali kemudian Konfusianisme dan atau Neo-Konfusianisme. Para intelektual di China kemudian mempelajari kembali filosofi tersebut dan banyak diajarkan kembali kepada beberapa masyarakat yang berminat. Memasuki tahun 1990-an ketika China mengalami pertumbuhan ekonomi yang bagus, mulai muncul kekhawatiran dari dalam negeri Chinaakan adanya penurunan nilai-nilai moral (Adler 2011). Ini menjadi salah satu penyebab kembalinya NeoKonfusianisme sebagai dasar filosofi dan budaya masyarakat China dalam menjalankan kehidupannya. Ini dilakukan karena dimungkinkan adanya upaya untuk membangkitkan kembali semangat dan etos masyarakat China. Sehingga, mobilisasi semacam ini akanmembantu proses pembangunan China yang terus berjalan.

\section{Simpulan}

Budaya berkontribusi terhadap pembangunan negara. Pembangunan tidak hanya didorong oleh hadirnya institusi-institusi formal namun juga oleh hadirnya institusi-institusi informal dimana budaya hadir dan berperan disitu. Jepang, Korea Selatan dan China kemudian menggunakan budaya sebagai bagian dari motor penggerak perekonomiannya. Di tiga negara ini, budaya kolektif konfusian dipadukan dengan budaya individu kapitalisme yang diimpor dari Barat. Proses penyerapan dan seleksi atas budaya-budaya lokal dan impor ini dilakukan lewat tahapan-tahapan humiliation di masing-masing negara.

Jepang mengawalinya lewat restorasi Meiji dan menghasilkan fukoku kyohei atau memperkaya negara dan memperkuat milter;wakon yosai atau jiwa Jepang dengan kemampuan Barat; datsua nyuo atau tinggalkan Asia dan bergabung dengan Eropa; serta bunmei keika atau menjadi beradab. Selain itu Jepang juga melakukan imitasi terhadap model keorganisasian barat. Proses humiliation di Korea Selatan menghasilkan budaya-budaya han yaitu rasa benci pada mereka yang telah menyakiti Korea dan sebagai dasar dalam mengejar ketertinggalan dalam pembangunan ekonomi; penciptaan chaebol dimana ada kerjasama antara negara, industri dan akademisi; family law yang menggerakkan seluruh energi negara kepada pembangunan; dan 
hadirnya hallyu. Proses penghinaan di China memunculkan pragmatisme, sosialisme ala China, dan Neo-Konfusianisme. Periodeperiode humiliation yang dialami oleh China ini telah menghilangkan budaya-budaya isolasionisme, Maoisme, ofisialisme, dan entrepreneurial familism.

\section{Referensi}

\section{Buku}

Bhabha, Homi K, 1990. Nation and Naration. New York: Routledge.

Berger, PL., 1986. The Capitalist Revolution: Fifty Propositions about Prosperity, Equality, and Liberty. New York: Basic.

Berger, PL., 1988. "An East Asian Development Model?" dalam PL Berger dan Michael Hsiao (ed), 1988. In Search of an East Asia Development Model. New Brunswick, New Jersey: Transaction Books.

Cullen, Louis M, 2003. A History of Japan, 1582-1941: Internal and External Worlds. Cambridge: Cambridge University Press.

Gluck, Carol, 1985. Japan's Modern Myths: Ideology in the Late Meiji Period. Princeton: Princeton University Press.

Goldstone, Jack A, 1991.Revolution and Rebellion in the Early Modern World. California: University of California Press.

Harrison, L. 2000. "Promoting progressive cultural change", dalam LE. Harrison dan S Huntington (eds.), 2000. Culture Matters: How Values Shape Human Progress. New York: Basic Books.

Hong, Euny, 2014. Korean Cool. Yogyakarta: Penerbit Bentang.

Inkster, Ian, 2001. The Japanese Industrial Economy: Late Development and Cultural Causation. London: Routledge.

Lipman, Jonathan Neaman, \& Stevan Harrell, 1990. Violence in China : Essays in Culture and Counterculture. New York: SUNY Press.

Morishima, Michio, 1982. Why Has Japan 'Succeeded'? Western Technology and Japanese Ethos. Cambridge: Cambridge University Press.

Pye, Lucian W, 1990. "The New Asian Capitalism: A Political Potrait" dalam Peter L Berger dan Hsin-Huang Michael Hsio (ed). 1990. In Search of an East Asian Development Model. London: Transaction Publishers.

Seth, Michael J. 2011. A History of Korea, From Antiquity to the Present. Plymouth: Rowman \& Littlefield Publishers.

Westley, D.E., 1987. Imitation and Innovation: The Transfer of Western Organizational Patterns to Meiji Japan. New York: to Excel 


\section{Jurnal}

Adams, Gerard dan Heidi Vernon, 2007. "Evaluating the "Asian Culture/Asian Success" Hypothesis", Journal of Asia-Pacific Business, 8(4): 5-20.

Allen, Michael W et all, 2007. "Two Decades of Change in Cultural values and Economic Development in Eight East Asian and Pacific Island Nations", Journal of Cross-Cultural Psychology, 38(3): 247-269.

Callahan, William A., 2004. "National Insecurities: Humiliation, Salvation and Chinese Nationalism", Alternatives: Global, Local, Political, 29(2): 199-218.

Crawford, Neta C., 2000. "The Passion of World Politics", International Security, 24(4): 116-156.

Greif, Avner, 1994. "Cultural beliefs and the organization of society: a historical and theoretical reflection on collectivist and individualist societies", The Journal of Political Economy. 102(5): 912-950.

Guiso, Luigi, Paola Sapienza dan Luigi Zingales, 2006. "Does culture affect economic outcomes?”, Journal of Economic Perspectives, 20(2): 23-48.

Hahm, C., Paik, W. 2003. "Logistic Confucianism and Economic Development in East Asia”, Journal of East Asian Studies,3(3): 461-491.

Kitahara, Michio, 1986. "The Rise of Four Mottoes in Japan: Before and After the Meiji Restoration", Journal of Asian History, 20(1): 5464

Lary, Diana, 2010. "China and Japan at War: Suffering and Survival, 1937-1945", The Asia-Pacific Journal, 8(2): 1-6.

Lin, Justin Yifu, \& Dennis Tao Yang, 1998. "On the Causes of China's Agricultural Crisis and the Great Leap Famine", China Economic Review, 9(2): 125-140

Power, Damien et all, 2009. "The Cultural Characteristic of Individualism/Collectivism: a Comparative Study of Implications for Investment Operations Between Emerging Asian and Industrialized Western Countries", Journal of Operations Management. 28: 206-222.

Rosker, Jana S., 2014. "China's Modernisation: From Daring Reforms to a Modern Confucian Revival of Traditional Values", Anthropological Notebooks, 20(2): 89-102.

Saurette, Paul. 2006. "You Dissin Me? Humiliation and Post 9/11 Global Politics", Review of International Studies, 32(3):495-522.

Xing, T, 2001. "The Idea of Plurality and Unity in the Configuration of the Chinese Nationality and China's Bilingual Education for Its Ethnic Minority”, Chinese Education \& Society, 34(2):75-90. 


\section{Online}

Adler, Joseph A., 2011. "Confucianism in China Today", Pearson Living Religions Forum, 14 April.

Goldfinger, Shandra, 2006. Lasting Effects of the Opium War. dalam : https://www.mtholyoke.edu/ goldf20s/politics116/effects.html [diakses 23 Mei 2016].

Magnus, George. 2013. “Asia's Fading Economic Miracle”.Centre for European Reform. dalamhttps://www.cer.org.uk/sites/default/files/publications/at tachments $/ p d f / 2013 / p b \_m a g n u s \_11 j a n 13-6814 . p d f[$ diakses 13 Juli 2016]

\section{Working Paper}

Barro, Robert J dan Rachel M McCleary, 2003."Religion and Economic Growth", Working Paper, No. 9682. 